\title{
ESTUDOS LINGÜíSTICOS
}




\title{
CRÍTICAS AO AURÉLIO
}

\author{
Antônio José Sandmann*
}

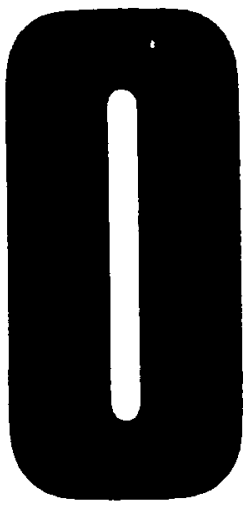

trato constante com a formaçāo de palavras no português brasileiro contemporâneo tem nos levado a consultar diuturnamente o Novo Dicionário Aurélio, daqui para frente chamado abreviadamente $A u$ rélio. Reconhecendo embora a grande realização que é o dicionário de Aurélio Buarque de Holanda Ferreira, temos algumas críticas a fazer a essa obra, sendo que essas divergências têm fundamento, possivelmente, em posturas diferentes diante do léxico da língua, a do lexicógrafo, por um lado, e a do morfólogo preocupado principalmente com a estrutura e formação de palavras, por outro. Um exemplo, para ilustração: o Aurélio registra dois verbetes -ada: $-a d a^{1}$ e $-a d a^{2}$, sendo que de $-a d a^{2}$ diz que é um sufixo nominal e que indica "espécime de plantas" (labiada), ao que nada temos a

* Universidade Federal do Paraná. 
opor. Já em -ada', também sufixo nominal, temos uma série de significados ou funçōes: "ação" ou "resultado de ação enérgica": freada, unhada; "coleçāo", "multidào": boiada, cumeada; "golpe": pedrada, facada; "produto alimentar": goiabada, laranjada; "duração": noitada, temporada; "porção": colherada; "marca feita com um instrumento": pincelada. O que causa estranheza no trato desse verbete? Em primeiro lugar, o Aurélio nāo dá a origem, como ele faz

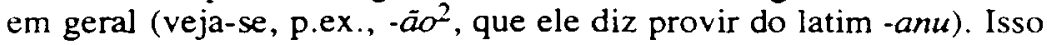
é estranho, de vez que o Aurélio adota o critério etimológico para o estabelecimento dos verbetes (veja-se o item 12. do Prefácio), sendo que a identidade de origem, nāo obstante a diversidade de funçōes ou de significados, seria um critério a justificar o trato dado. Porém, mesmo adotando o critério etimológico, é difícil tratar num mesmo verbete um elemento que faz de um verbo um substantivo (caminhar $+-a d a=$ caminhada) e um elemento que faz de um substantivo um outro substantivo (canivete + -ada $=$ canivetada), sem esquecer que, mesmo quando o produto é um outro substantivo, a semântica é, em geral muito diversa: goiabada, exemplo de produto alimentar, e boiada, exemplo de coletivo. Críticas menores seriam que ele nāo registra a variante popular e de conteúdo em geral depreciativo - arada (homarada, netarada, veadarada) e quando diz que o sufixo - ada ${ }^{2}$ expressa "açāo" ele se esquece de dizer que muitas vezes essa ação é breve: (dar uma) estudadalpasseada, além de nāo dar a semântica exata do sufixo -ada em churrascada, cervejada e chopada "reunião em que se come/bebe churrasco/cerveja/chope".

As dimensões do presente trabalho levam-nos naturalmente a abordar apenas alguns aspectos.

\section{COMPOSTO X GRUPO SINTÁTICO}

Em SANDMANN (1990) procurou-se estabelecer critérios de distinçāo entre composto ou palavra composta de um lado e grupo sintático permanente ou fixo e eventual de outro. Foi dito lá, entre outras coisas, que o critério semântico é o que mais nos socorre em português para isolar ou diferençar o composto do grupo sintático paralelo. Copo-de-leite "a flor" e bóia-fria "trabalhador rural sem vínculo empregatício", por exemplo, são compostos - e por isso grafados com hífen - pelo critério semântico: em copo-de-leite temos uma metáfora e em bóia-fria, uma metonímia. Voltando-nos para o objetivo do presente estudo e considerando aspectos semânticos, perguntaria por que o Aurélio nảo considera compostos peso-leve, peso-médio e peso-pesado "categorias do boxe ou os lutadores en- 
quadrados nessas categorias do boxe", nome-de-guerra "nome pelo qual alguém é chamado comumente", dona-de-casa "a mulher enquanto administra o lar", zero-à-esquerda "pessoa sem nenhum valor", dia-de-semana "dia útil" e ovelha-negra "pessoa de mau comportamento"? O Aurélio trata essas seqüências como grupos sintáticos permanentes nos verbetes, respectivamente, peso, nome, dona, zero, dia e ovelha, grafando-as, conseqüentemente, sem hífen.

Com base principalmente no critério sintático - pois não é própria da frase a seqüência de dois substantivos pertencentes ao mesmo sintagma - são considerados compostos trem-bala, peixe-espada, peso-mosca e banho-maria, p.ex., seqüências lingüísticas fixas do português que rotulam ou dão nome a entidades ou processos do nosso universo biofisicossocial. Se esse critério é válido e o próprio Aurélio tem como norma segui-lo, pergunto por que o dicionarista nāo grafa efeito-estufa e operaçāo-tartaruga, mas omite o hífen e não dá a essas seqüências tratamento de verbetes autônomos? No verbete desvio o Aurélio traz desvio padrão, sem hífen, o que é uma incoerência, pois no verbete padrão nāo diz que é adjetivo além de substantivo. Aliás, no jomal Folha de São Paulo, de 28.05.89, p.I-14, ocorre desvio-padrāo e Miriam Lemle, em Análise Sintática, Ática, 1984, grafa, na capa, modelo-padrāo e teoria-padrão. Nos verbetes curta-metragem e longa-metragem é dito que sāo abreviaçōes, respectivamente, de filme de longa-metragem e filme de curta metragem, uma vez com hífen, outra vez sem, sendo que.a grafia correta é sem hífen.

\section{POLISSEMIA E HOMONÍMIA}

Como bem observou LYONS (1981), "talvez devêssemos nos conformar com o fato de que o problema de distinguir entre homonímia e polissemia é, em princípio, insolúvel." Mesmo assim, o lexicógrafo tem de estabelecer critérios de procedimento diante de palavras envolvidas em aspectos de polissemia e homonímia e, principalmente, agir coerentemente depois de estabelecidos os critérios. Também aqui o Aurélio é passível de algumas críticas. Como já foi observado no início deste estudo, o Aurélio abre dois verbetes - ada, sem justificar tal procedimento dando a etimologia, possivelmente diversa, de ambos. No caso de $-\bar{a} o$, há três verbetes: $-\tilde{a} o^{1}$, de que não é dada a origem, $-\bar{a} o^{2}$, de que é dito que vem do lat. -anu, e $-\bar{a} o^{3}$, de que é dito que é sufixo vernáculo, o que é questionável, porque dá a entender que se formou dentro do português, sem ligação com o latim, sendo que o próprio Aurélio diz que $-\tilde{a} o^{3}$ é equi- 
valente a -çāo (do lat. -tione) e -(s) são (do lat. (s) sione). Para os substantivos terminados em -vel ele registra a forma -ável, esquecendo-se de que há os em -ável (provável), os em -ivel (inesquecível) e -ével (indelével). $O$ fato de seguir apenas o critério etimológico ou da origem tem, no Aurélio, conseqüências como as seguintes: palavras de outra classe gramatical, poder "verbo" e poder "substantivo", mas da mesma origem, e palavras de outra semântica apesar da mesma origem, segundo "numeral ordinal" e segundo "unidade de tempo", p.ex., são tratadas no mesmo verbete. Pergunta-se: será que esse critério é suficiente? Não seria melhor invocar um segundo, o formal ou sintático, sendo que poder "verbo" e poder "substantivo" dariam poder e poder ${ }^{2}$ e segundo", numeral ordinal, e segundo "medida de tempo", substantivo, seriam verbetes distintos, ao lado de segundo " "conforme", preposiçāo, e até um terceiro critério, o semântico, segundo o qual teríamos cálculo" "operaçāo aritmética" e cálculo 2 "concreçāo em vísceras"?

Outra situaçāo em que falta clareza é no trato de $-\bar{a} o^{1},-\bar{a} o^{2}$ e $-\tilde{a} o^{3}$. Só para citar um exemplo, nāo há nesses verbetes o trato do -āo de agentivos derivados de verbos como choräo, respondāo e resmungão, sendo que nos verbetes respondäo e resmungão é dito que eles contêm o sufixo $-\bar{a} o^{3}$, próprio de nomes de ação formados a partir de verbos: escorregāo, puxäo, e no verbete chorāo nada é dito sobre sua estrutura.

\section{O QUE DICIONARIZAR?}

Referindo-se ao fato de que no dicionário de Walker os advérbios em $-l y$, do inglês, ocupam 34 páginas, diz ARONOFF (36s.): We feel somehow that it is superfluous. Cremos que a impressão de superfluidade também nos vem diante de muitos registros com o prefixo re-, do Aurélio: por que registrar, p.ex., refinanciar e reinvestir, em que re-significa simplesmentee "de novo", formaçōes, portanto, inteiramente transparentes? Com o prefixo recém- o Aurélio registra poucos verbetes, mesmo assim em sua maioria dispensáveis. No caso de ex-, na funçāo de indicar "situaçāo, posição ou cargo anterior", o Aurélio só registra esse verbete (ver $e^{2}$ ) com exemplos, e nenhum verbete mais, o que é correto, pois essas formaçōes (exprofessor, ex-aluno) são inteiramente transparentes. Não vamos estender nossas consideraçōes sobre formaçōes com outros prefixos (in- negativo e des-, entre outros) ou sobre formaçōes com sufixos porque nāo o permitem as dimensōes deste trabalho, mas fica o leitor alertado para o que um lexicógrafo deve registrar e para o que ele 
pode perfeitamente dispensar, por mais completa ou exaustiva que sua obra ambicione ser. Esse fato está naturalmente ligado a fatores de produtividade e transparência. Nāo se espera, p.ex., que o Aurélio registre garfão e garfinho, e ele realmente nāo o faz, mas espera-se que ele registre facão, e ele o faz, não dizendo, no entanto, simplesmente que é o aumentativo de faca, pois facão é lexicalizado também, sendo que, se nāo o fosse, nāo poderíamos ter facāozão e facãozinho.

\section{DIACRONIA E SINCRONIA}

Objetiva-se nesta seção mostrar que o Aurélio não tem sempre uma linha coerente no assinalamento de aspectos da origem, aspecto diacrônico, e da estrutura, aspecto sincrônico, dos verbetes. Em passável, p.ex., é dada apenas a estrutura (passar + ável), em amável é dada a origem (do lat. amabile), mas não é dada a estrutura e em louvável nāo há nem a origem, nem a estrutura. Ao lado disso registra trafegável sem apresentar origem e estrutura e em intrafegável apresenta apenas a estrutura (in- + trafegar $+-v e l$ ), uma derivaçāo parassintética, portanto, sem relacioná-lo com trafegável, o que é, aliás, defensável, pois muitos adjetivos com o sufixo-vel sāo mais freqüentes com o prefixo simultâneo negativo in- do que sem esse prefixo: insubstitutvel, inadmissível, inolvidável, etc.

Em permissibilidade o Aurélio não dá nem origem, nem estrutura e em admissibilidade dá a estrutura, misturando aspectos diacrônicos com sincrônicos (do lat. admissibile $+-i+-$ dade), com um erro, aliás, pois a forma do sufixo é -idade, sendo a forma -dade (de bondade, p.ex.) a exceção e hoje improdutiva. Por outro lado, em admissivel não encontramos nem estrutura, nem origem, ao passo que em permissível, preocupado em relacionar essa forma com permitir, o Aurélio diz o seguinte: "do lat. permissu, part.pass. de perimittere, 'permitir', + tvel."

De repatriar nosso lexicógrafo diz apenas que procede do lat. repatriare e em expatriar é dada somente a estrutura: ex- + pátria + -ar, formação parassintética. Finalmente, de fomentar e fomentaçāo é dito que procedem dos latinos fomentare e fomentatione, nāo sendo dada a estrutura de fomentação, e de fomento, "ato ou efeito de fomentar, fomentação", não é dito que é deverbal de fomentar, como o Aurélio sói fazer nesses casos de derivação regressiva, mas é dada uma etimologia esdrúxula e sem nenhum nexo com a semântica apresentada: "sing. do lat. fomenta, orum, 'gravetos'". 


\section{LACUNAS}

A título de ilustração alguns exemplos de falhas ou omissōes registradas no Aurélio. Não há distinção entre -tório ${ }^{1}$, sufixo formador de substantivos a partir de verbos e que significa "lugar onde. . ." (purgatório, dormitório), sinônimo de -douro ${ }^{1}$ (vertedouro, ancoradouro), e -tório ${ }^{2}$, sufixo formador de adjetivos dinâmicos a partir de verbos (inibitório, discriminatório), formaçōes que o Aurélio registra mas sem lhes indicar a estrutura. O sufixo -tório é, aliás, ainda produtivo, sendo que recentemente registramos indenizatório e celebratório (jornal Folha de Sāo Paulo, de 25.08.90, p.B-2 e 11.09 .90 , p.A-2). Os sufixos -imo (humitimo), -érrimo (celebérrimo) e -ésimo (enésimo), os dois últimos hoje produtivos em formações da variante informal da língua (cafonérrimo. chiquésimo), não encontram registro em verbetes independentes como o Aurélio sói fazer com os prefixos e sufixos. Também nāo encontramos o sufixo -anca (potranca, carranca). No verbete -mente, finalmente, só é dada a semântica "maneira", "modo", sendo esquecidas formaçōes como antigamente, modernamente e ofinalmente empregado no início deste período.

\section{ERROS}

Finalmente alguns casos em que não temos simplesmente lacunas ou questões de critérios discutíveis ou insuficientes. Trata-se de erros mesmo. Devassa e baixa, p.ex., enquanto substantivos que significam "ato de devassar/baixar", sāo substantivos deverbais, chamados também derivaçōes regressivas, e não são o feminino de devasso/baixo como quer o Aurélio. Mergulhäo "pato que mergulha" nāo pode ser considerado aumentativo de mergulho, porém agentivo formado de mergulhar $+-a ̈ o$, como temos em chorão, resmungão, etc. O português conhece hoje um modelo de formação de substantivos/adjetivos em -ável cuja base é um substantivo e não um verbo: presidenciável, reitorável. Causa, pois, estranheza ler no Aurélio que ministeriável vem "de um ministeriar + -avel". Nosso dicionário em análise traz um verbete radiogravador, um composto copulativo, que devia ser grafado rádio-gravador, como é grafado auto-escola, pois como neste exemplo, rádio não é o elemento de composição, radical preso radio-, porém a forma abreviada de radiofonia, como o próprio Aurélio admite. Achamos, por último, pouco técnica a definiçāo de prefixo, enquanto morfema que entra na formação de palavras: "Snaba(s) que antecede(m) a raiz de uma pala- 
vra. ..". Ora, prefixos são morfemas, unidades lexicais, em geral portadoras de significado, enquanto silabas são unidades rítmicas, unidades fonéticas, têm a ver com aspectos articulatório-auditivos, sendo que não se pode definir aqueles por estas.

\section{RESUMO}

No trato diuturno com a formação de palavras novas no português brasileiro contemporâneo as consultas ao Novo Dicionário Aurélio da Língua Portuguesa têm sido uma constante. Pois bem, esse folhear constante do Aurélio nos tem levado à descoberta de numerosas lacunas ou falhas e de falta de sistematicidade, como, por exemplo de passável dar a estrutura (passar + -ável), de amável dar só a origem latina (amabile) e de analisável nāo dar nem a origem nem a estrutura.

\section{REFERÊNCIAS BIBLIOGRÁFICAS}

1 ARONOFF, M. Word Formation in Generative Grammar. Cambridge, Mass. : MIT Press, 1976.

2 LYONS, J. Language and Linguistics - an Introduction. Cambridge : University Press, 1981.

3 SANDMANN, A.J. Formaçāo de Palavras no Ponuguês Brasileiro Contemporâneo. Curitiba : Scientia et Labor, 1989.

4 O que é um Composto. D.E.L.T.A. v.6, n.1, p.1-18, 1990.

5 Polissemia e Homonímia. In: NEVES, M.H. de M. Descrição do Português. SERIENCONTROS (1-12). 1990. 